\title{
Characteristics of the ionospheric total electron content of the equatorial ionization anomaly in the Asian-Australian region during 1996-2004
}

\author{
Biqiang Zhao ${ }^{1}$, Weixing Wan ${ }^{1}$, Libo Liu ${ }^{1}$, and Zhipeng Ren ${ }^{1,2,3}$ \\ ${ }^{1}$ Beijing National Observatory of Space Environment, Institute of Geology and Geophysics, Chinese Academy of Sciences, \\ Beijing, China \\ ${ }^{2}$ Wuhan Institute of Physics and Mathematics, CAS, Wuhan, China \\ ${ }^{3}$ Graduate School of Chinese Academy of Sciences, Beijing, China
}

Received: 7 April 2008 - Revised: 7 October 2008 - Accepted: 26 November 2008 - Published: 12 October 2009

\begin{abstract}
Ionospheric total electron content (TEC) of the equatorial ionization anomaly (EIA) is studied by analyzing dual-frequency signals of the Global Position System (GPS) acquired from a network of receivers around the AsianAustralian region during 1996-2004. The latitude, occurrence time, strength of the most developed EIA crest, and crest-to-trough ratio (CTR) for both the noon and post-sunset sector obtained from a daily TEC contour map have been used to study the solar cycle variations of EIA in the AsianAustralian region. The results reveal that semiannual and seasonal variations were the dominant factor that controls the morphology of the EIA structure which can be identified in the past studies (e.g. Wu et al., 2008). It is also found that the latitude and local time position of the anomaly crest show a hemispheric asymmetry because (a) The northern crest of EIA is expanded during the equinox indicating a weak semiannual variation while the southern crest is inhibited during June-August presenting a strong seasonal variation, and (b) The local time of the northern crest appears $\sim 1.3 \mathrm{~h}$ earlier than that of the southern crest in June while showing no difference at December. Solar activity dependence is more evident in the EIA crest region than in the EIA trough region and least in the post-sunset sector at equinox. A seasonal linear relationship is derived between the post-sunset CTR and solar flux, which should be caused by the solar-dependant equatorial $\boldsymbol{E} \times \boldsymbol{B}$ vertical drift.
\end{abstract}

Keywords. Geomagnetism and paleomagnetism (Spatial variations (all harmonics and anomalies)) - Ionosphere (Equatorial ionosphere) - Magnetospheric physics (Electric fields)

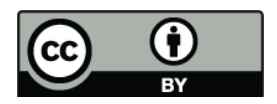

Correspondence to: Biqiang Zhao (zbqjz@mail.iggcas.ac.cn)

\section{Introduction}

The equatorial ionization anomaly (EIA), also termed equatorial ionospheric anomaly by some scientists, is a most common feature at low and equatorial latitudes in the ionosphere. It is characterized by a trough at the magnetic equator and two humps at about $15^{\circ}$ either side of the magnetic equator. Its daytime development occurs under the action of the Elayer tide-induced dynamo electric field driving the F-region plasma vertically up and then diffusing away from the magnetic equator under the pressure gradient force and gravity (Stening, 1992). The persistence of the EIA well into the night, depending on the season and solar activity, is known to be produced by the evening enhancement in the eastward electric field generated by the F-region dynamo action resulting from the eastward component of the thermospheric wind blowing in the region of the decreasing day-to-night E-layer Pederson conductivity distribution (Heelis, 2004). The investigation of the EIA is important for its practical objectives. The development and decay of EIA produces a large latitudinal disturbance of F-region plasma in the lower latitude belt in the post-sunset hours and the occurrence of various low latitude phenomenon observed in the ionospheric electron content (Dabas et al., 2006). The EIA is responsible for the global maximum values of the ionospheric total electron content (TEC) over tropical latitude that influences the UHF radio propagation range determinations based on GPS satellite signals. Besides, it contributes to the enhanced ionospheric scintillations effects produced by spread F/plasma bubbles irregularities on trans-ionospheric radio wave propagations (e.g. Whalen, 2003; Basu et al., 2004; Abdu, 2005).

In the Southeast Asian region, the study of TEC EIA structure can be traced back to the work of Golton and Walker (1971) based on the recording of the Faraday rotation of signals from the geostationary satellite at Hong Kong

Published by Copernicus Publications on behalf of the European Geosciences Union. 


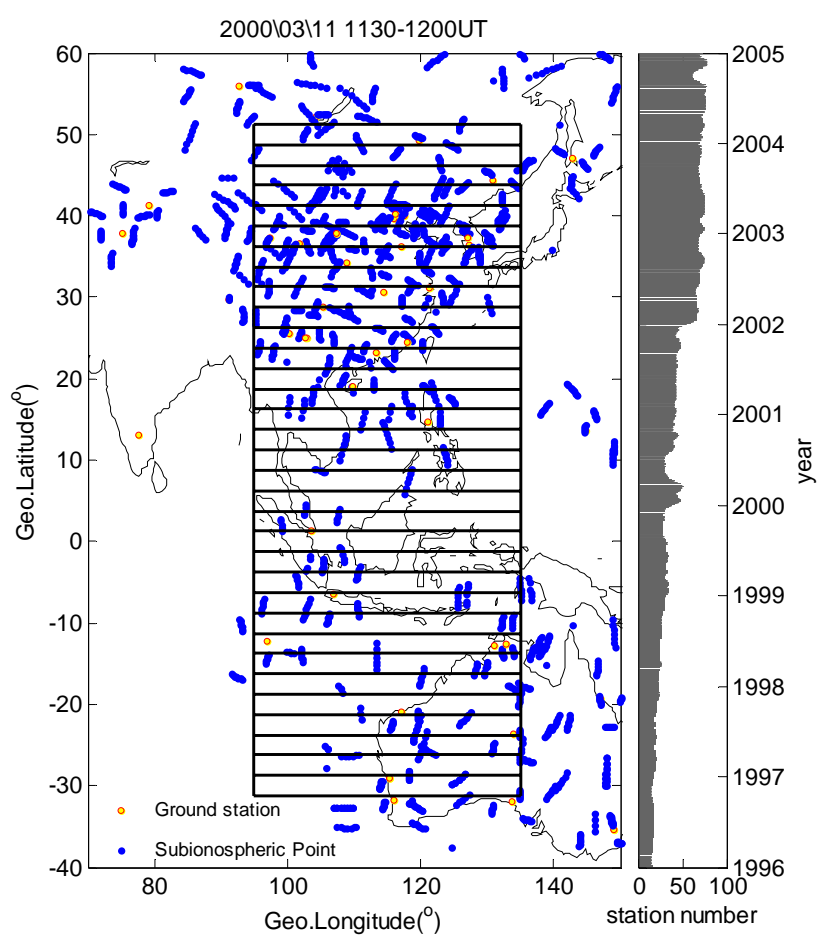

Fig. 1. Distribution of GPS receivers around Asian-Australian region. The dots represent the sub-ionospheric point track of the GPS satellites during 11:30-12:00 UT on 11 March 2000. The area centered at $115^{\circ}$ from $50.125^{\circ} \mathrm{N}-30.125^{\circ} \mathrm{S}$ was separated into 33 boxes with $40^{\circ}$ width. By using least square fit and nearest neighbor interpolation method, slant TEC observations are converted to vertical TEC data of the corresponding box.

$\left(22.2^{\circ} \mathrm{N}, 114.2^{\circ} \mathrm{E}\right)$ and Singapore $\left(1.4^{\circ} \mathrm{N}, 103.8^{\circ} \mathrm{E}\right)$. Since then, succedent work has been performed to investigate EIA evolution feature associated with local time, season under different solar activity phase including comparison with the results of the other longitude (e.g. Walker and Ma, 1972; Walker and Poon, 1977; Walker et al., 1991, 1994). In the 90s of last century, Huang and Cheng (1996) studied solar cycle variations of the northern EIA in TEC during the period 1985-1994 with radio signals transmitted from the US Navy Navigation Satellite System (NNSS) satellites and received by a single ground station at Lunping $\left(25.0^{\circ} \mathrm{N}, 121.2^{\circ} \mathrm{E}\right)$. They derived a linear relationship between the strength of the EIA crest and sunspot number. However, they found no significant solar cycle effect in the occurrence time and latitude of the most developed EIA northern crest. They also found that the winter crest appears larger and earlier than the summer crest, and the summer crest appears lower in latitude than during other seasons. Tsai et al. (2001) used two stations (YMSM: $25.2^{\circ} \mathrm{N}, 121.6^{\circ} \mathrm{E}, \mathrm{DGAR}: 7.3^{\circ} \mathrm{S}, 72.4^{\circ} \mathrm{E}$ ) of the year 1997 to investigate the seasonal variations of the ionospheric TEC at both the northern and southern EIA crest region. Their results show that both crests are fully devel- oped around midday in winter, postnoon in equinoxes and late afternoon in summer, and the two crests move significantly equatorward in winter but slightly poleward in summer and autumn.

Since the longitudinal and latitudinal extent of the ionospheric anomaly is large, the temporal and spatial behavior of the anomaly cannot be simultaneously monitored with a single station. With an unprecedented spatial resolution, $\mathrm{Wu}$ et al. $(2004,2008)$ studied ionospheric TEC in the northern hemispheric equatorial anomaly region during 1994-2003 by analyzing dual-frequency signals from the global position system (GPS) acquired from a meridional chain of 9 observational sites clustered around Taiwan $\left(21.9^{\circ}-26.2^{\circ} \mathrm{N}, 118^{\circ} 4\right.$ $\left.121^{\circ} 6 \mathrm{E}\right)$. For the first time, they found that the monthly values of $I_{c}$ (magnitude of TEC at the northern anomaly crest) correlate well with the $D_{s t}$ geomagnetic activity index during low solar activity. They also revealed a weak semiannual variation in the northern EIA crest latitude - the winter and summer crests occurred at lower latitudes than the spring and autumn ones.

Recently, Liu et al. (2007) investigated the solar activity dependence of the electron density at $400 \mathrm{~km}$ altitude in the whole equatorial anomaly regions through CHAMP observation. They found that the electron density in the crest regions of the EIA grows roughly linearly from solar minimum to solar maximum, with a higher growth rate than that in the EIA trough region. They also revealed that the growth rate of the electron density with increasing solar activity around equinoxes is about 1.5 to 2 times greater than that near the solstices. They have introduced the crest-to-trough (CTR) parameter defined as $\left(\mathrm{Ne}_{\text {ncrest }}+\mathrm{Ne}_{\text {screst }}\right) /\left(2 \mathrm{Ne}_{\text {trough }}\right)$ similar to that given by Mendillo et al. (2000), and found the solar activity dependence of CTR varies significantly with local time. A theoretical study of electron density distribution in the nighttime equatorial ionosphere, shows that linear relationships with statistically significant correlation coefficients exist between the maximum value of the post-sunset plasma drift velocity and the peak-to-valley ratio of anomaly TEC (Basu et al., 2004). The study is based on the low-latitude density model of Air Force Research Laboratory (AFRL) and the obtained relationships are valid for the longitudinal sector of Jicamarca incoherent scatter radar whose drift velocity measurements are used. The significance of their finding lies in the fact that the maximum value of the post-sunset vertical plasma drift velocity is an important parameter for determining both the intensity and the latitudinal distribution of equatorial scintillation. When the parameter is not available from any direct measurement, the linear relationships may be used to estimate it from the measured peak-to-valley ratio of anomaly TEC. This has also been pointed out by Whalen (2004), who found that the post-sunset equatorial ionization anomaly, with maximum F-layer electron density, $\mathrm{Ne}_{\max }$, occurring near 21:00 LT, to be a linear function of the maximum pre-reversal $\boldsymbol{E} \times \boldsymbol{B}$ drift velocity during solar maximum. 


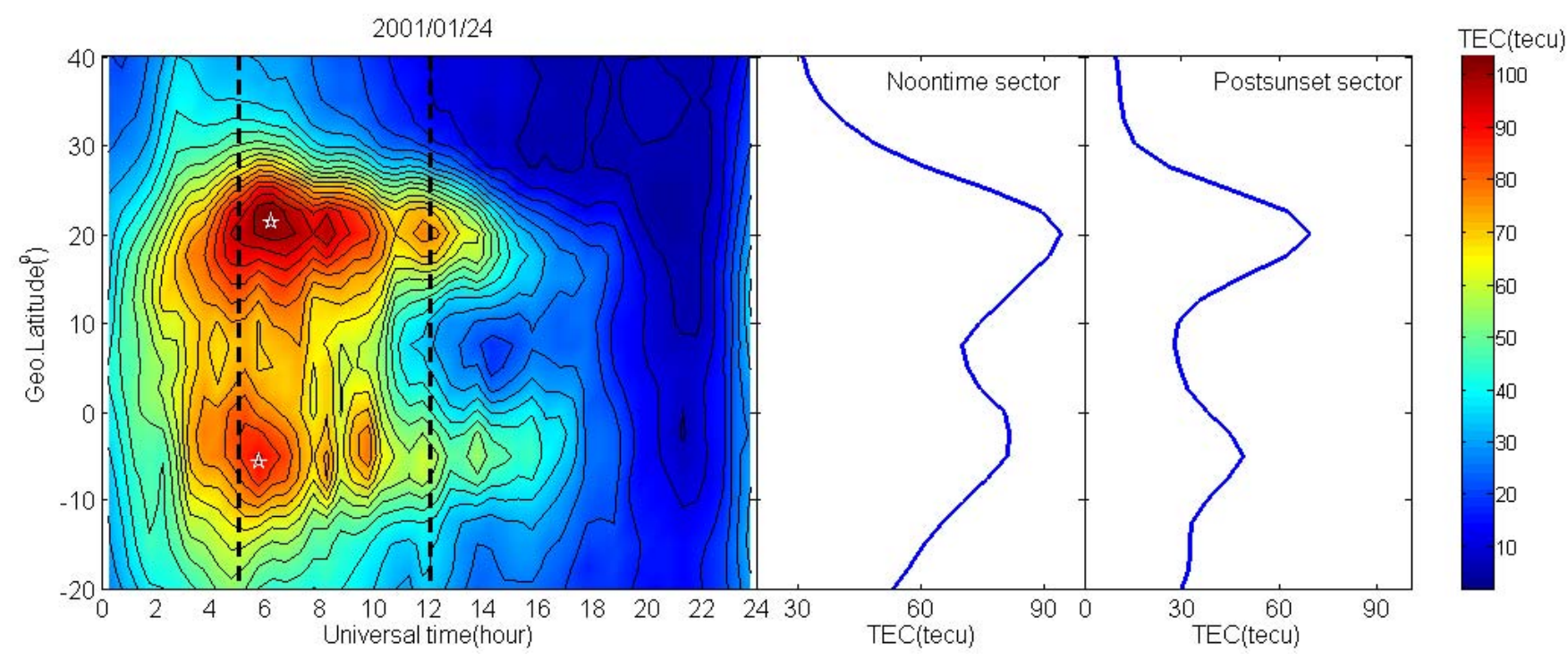

Fig. 2. Schematic TEC contour map in the UT/latitude frame (left panel) on 24 January 2001. The pentagons denote the position of daily peak value of EIA for northern crest and southern one, respectively. The vertical dashed lines indicate the local time 13:00 LT and 21:00 LT $(\mathrm{LT}=\mathrm{UT}+8)$. The corresponding TEC profiles are given in the right panels.

From 1996 to the present, with a constellation of more than 24 satellites and an ever-growing network of ground receivers, the GPS system has become the major source of the TEC data. This paper takes the advantage of GPS network around the Asian-Australian region to study the EIA climatology from 1996-2004. Different from the previous studies, we focus not only on the northern crest but also the southern crest and discuss the north-south asymmetry in the EIA crest features. We also studied the CTR in the noon and postsunset sector because of its dynamic nature and application purpose. This paper aims to present the inherent characteristics of EIA in the Asian-Australian sector by investigating the parameters for both northern and southern EIA crest within a solar cycle.

\section{Measurements and data selection}

TEC can be derived from transionospheric GPS signals recorded at ground-based GPS receivers (Klobuchar, 1991). The general approach of combining the GPS pseudorange and phase measurements to extract slant TEC (STEC) with satellite and receiver biases has been described in detail in several literatures (Lanyi and Roth, 1988; Sardón, 1994). The total electron content along the GPS ray path from a satellite to a receiver is known as the STEC. The STEC can be obtained from the difference between the pseudoranges $\left(P_{1}\right.$ and $\left.P_{2}\right)$, and the difference between the phases ( $L_{1}$ and $\left.L_{2}\right)$ of the two GPS signals (Klobuchar, 1996). The relevant equations are:

$$
\begin{aligned}
\operatorname{STEC}_{L} & =\left[\left(\frac{f_{2}^{2}}{f_{1}^{2}-f_{2}^{2}}\right) \frac{2 f_{1}^{2}}{K}\right]\left(P_{2}-P_{1}\right) \\
\operatorname{STEC}_{P} & =\left[\left(\frac{f_{2}^{2}}{f_{1}^{2}-f_{2}^{2}}\right) \frac{2 f_{1}^{2}}{K}\right]\left(L_{1} \lambda_{1}-L_{2} \lambda_{2}\right)
\end{aligned}
$$

Where $f_{1}$ and $f_{2}$ are GPS signal frequencies and are equal to $1.57542 \mathrm{GHz}$ and $1.2276 \mathrm{GHz}$, respectively, $K=80.62 \mathrm{~m}^{3} \mathrm{~s}^{-2}$ is a constant that relates plasma frequency to electron density, $\lambda_{1}$ and $\lambda_{2}$ are the wavelengths corresponding to $f_{1}$ and $f_{2}$. The STEC from differential phase $\left(\mathrm{STEC}_{P}\right)$ are less affected by multi-path effects (Klobuchar, 1996; Jakowski et al., 1996), and thus it provides smoother and high precision measurements of STEC. However, because of the $2 \pi$ ambiguity in phase measurements, the absolute value of STEC cannot be determined. Hence, we resort to the STEC from differential pseudoranges $\left(\mathrm{STEC}_{L}\right)$ because it can provide absolute values of TEC notwithstanding the multi-path effect. Therefore, to retain the relative accuracy of the phase path measurements, the $\mathrm{STEC}_{P}$ values for a given satellite pass are fitted to the level of the $\mathrm{STEC}_{L}$ measurements as $\mathrm{STEC}_{P}$ plus a RMS difference between $\mathrm{STEC}_{L}$ and $\mathrm{STEC}_{P}$, then the STEC can be expressed as:

$\mathrm{STEC}=\operatorname{STEC}_{P}+B_{\text {corr }}$

$B_{\text {corr }}=\sqrt{\sum_{i=1}^{N}\left(\operatorname{STEC}_{L}-\operatorname{STEC}_{P}\right)^{2} / N}$

$N$ are measurements obtained during a satellite pass. To convert STEC to vertical TEC (VTEC), it is customary to assume 


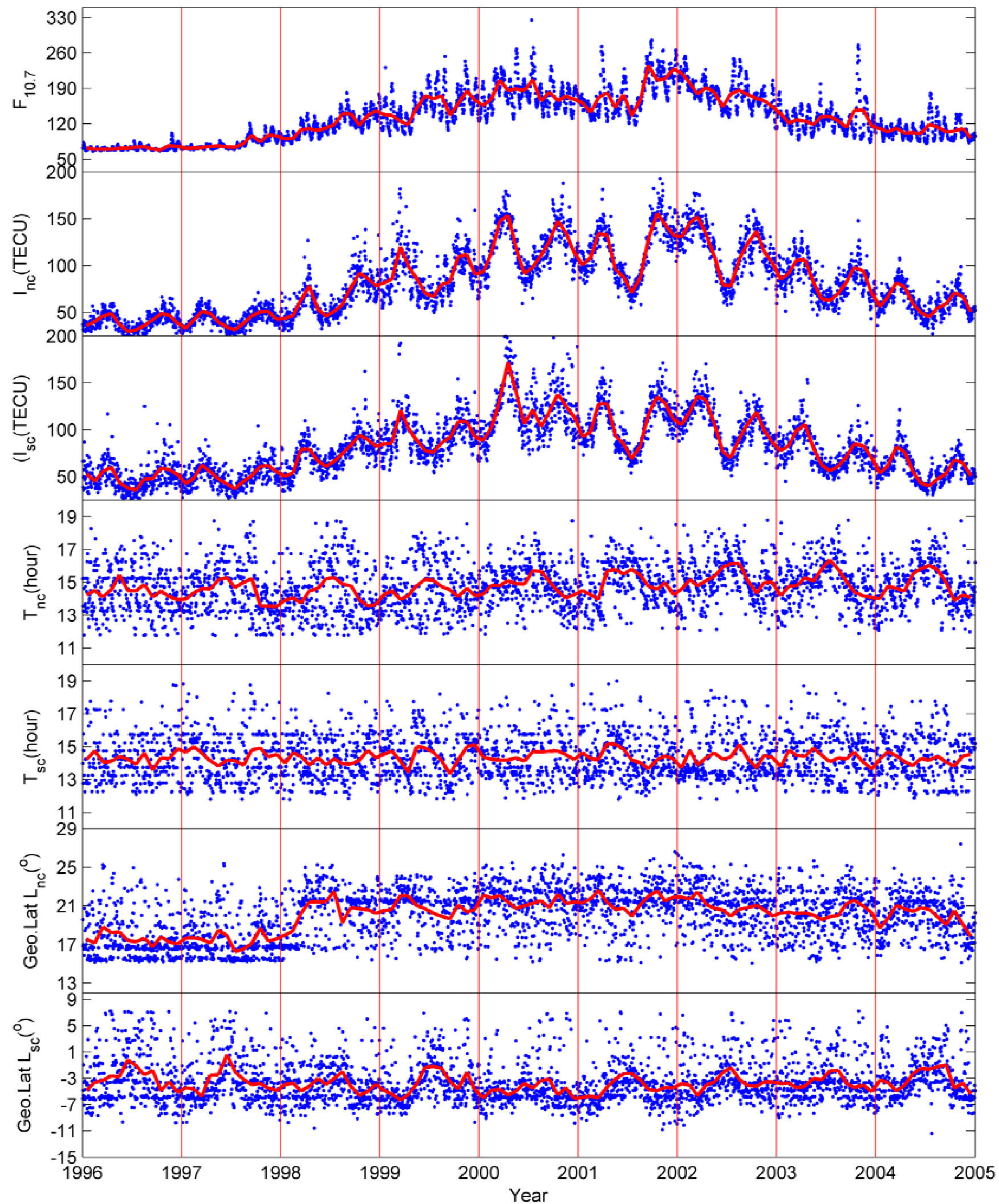

Fig. 3. From top to bottom are $\mathrm{F}_{10.7}$, the daily strength $(I)$, the occurrence local time $(T)$, and the geographic latitude $(L)$ for the northern $(n c)$ and southern $(s c)$ EIA crest, respectively. Solid lines show the variation of the corresponding monthly mean values. 
the Earth's ionosphere as a thin-shell model at a fixed height $\left(h_{s}\right)$ in the range $350-400 \mathrm{~km}$ (Klobuchar, 1996). The choice of a particular height of the thin shell is not particularly critical. Titheridge (1972) made extensive calculations with theoretical electron density profiles and showed that a global average height of $420 \mathrm{~km}$ is appropriate for oblique to vertical conversion. Using different thin-shell heights for different local times and seasons of the year, Breed (1996) demonstrated the magnitude of the error arising from an incorrect choice of median height are insignificant for measurements at an elevation angle greater than $15^{\circ}$. He found that $400 \mathrm{~km}$ is an appropriate height for the oblique to vertical conversion. For this paper, $h_{s}=400 \mathrm{~km}$ has been used to convert STEC to VTEC and is, therefore, mathematically given by:

$\mathrm{VTEC}=\left(\mathrm{STEC}-B^{S}-B_{R}\right)\left(\sqrt{1-\left(\frac{R_{e} \times \cos (\varepsilon)}{R_{e}+h_{s}}\right)^{2}}\right)$

$B^{S}$ and $B_{R}$ is the instruction biases of satellites and receivers respectively; $R_{E}=6371 \mathrm{~km}$ is the mean radius of the Earth; $\varepsilon$ is the elevation angle of the satellite. Since the GPS satellites are evenly distributed in 6 orbital planes, it is possible to adopt all the data of a GPS network to construct the TEC map. The coverage of the map is a function of the GPS satellites' orbit, the cut-off elevation angle and the altitude of the sub-ionospheric point. Figure 1 illustrates the subionospheric point track or ionospheric footprints of the GPS satellites observed at longitudes $70^{\circ}-150^{\circ} \mathrm{E}$ during 11:30 12:00 UT on 11 March 2000. There are 40 GPS receivers distributed in the map which were obtained from International Global Navigation Satellite System Service (IGS) and Crust Movement Observation Network of China (CMONOC) covering almost the whole Chinese sector. By incorporating a network of GPS receivers, a UT/latitude map can be reconstructed by applying nearest interpolation to the longitude $115^{\circ} \mathrm{E}$ with a $40^{\circ}$ window as shown in Fig. 1 . The latitude resolution is $2.5^{\circ}$ and temporal resolution is half an hour. Then, by using least square fit and nearest neighbor interpolation method STEC observations are converted to VTEC data of $2.5^{\circ}$ grid; at the same time, instrument biases are filtered out. The above process is based on the assumption that the longitude difference of EIA in this area is small and the error depends on the number of the GPS receivers. This interpolated TEC combined with the ionosonde observations has been used to study the ionospheric storm effects in the Asian-Australian and American regions during the "Halloween storm" (Zhao et al., 2005). As shown in the right panel of Fig. 1, the number of GPS receivers in this area increased year by year from 1996 to 2004. During 19961997, the number of GPS receivers is around 15-20 and also the intensity of EIA is not strong enough. The latitudinal distribution of EIA was sometimes represented with a maximum near the magnetic equator, and the EIA crest may also disappear during an intense magnetic storm. Hence, we will

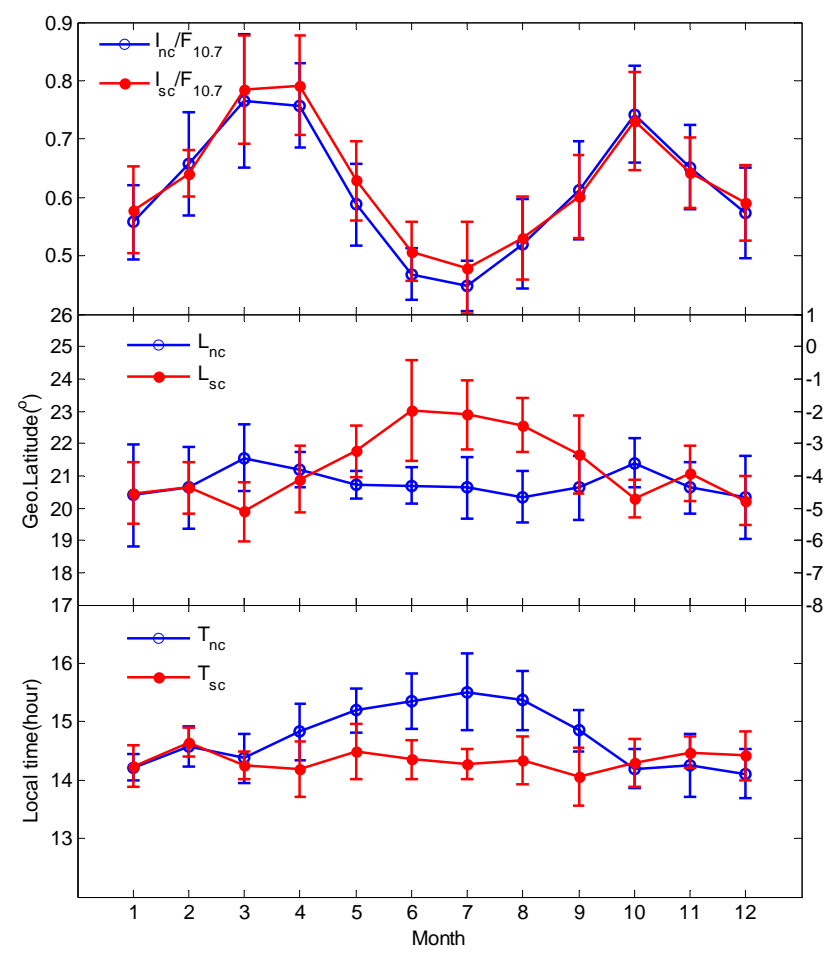

Fig. 4. Panels from top to bottom show monthly mean values over the 9 years of equivalent crest value per solar flux unit $\left(I / F_{10.7}\right)$, occurrence of geographic latitude $(L)$, and occurrence of local time $(T)$ for the northern $(n c)$ and southern $(s c)$ EIA crest. Vertical bars indicate one standard deviation.

exclude the above situations manually to avoid introducing errors.

Once the UT/latitude map of TEC was obtained, a contouring algorithm with the level being set at 20 (using the software Matlab 7.0) was applied to the map to acquire the peak value, as illustrated in Fig. 2. According to Huang and Cheng (1996) and Liu et al. (2007), several typical parameters can be used to characterize the structure of EIA: (1) the amplitude of the most developed northern (southern) crest $I_{n c}\left(I_{s c}\right)$, as well as its local time $T_{n c}\left(T_{s c}\right)$ and geographic latitude $L_{n c}\left(L_{s c}\right)$. (2) $\mathrm{CTR}^{1300}$ and $\mathrm{CTR}^{2100}$ (CTR at noon sector 13:00 LT and post-sunset period 21:00 LT). Accompanying CTR, four extra parameters will be introduced accordingly. $I_{c}^{1300}\left(0.5 \times I_{n c}^{1300}+0.5 \times I_{s c}^{1300}\right)$ and $I_{c}^{2100}$ $\left(0.5 \times I_{n c}^{2100}+0.5 \times I_{s c}^{2100}\right)$ are the equivalent strength of the crest peak while $I_{t}^{1300}$ and $I_{t}^{2100}$ are the strength of the EIA trough at 13:00 and 21:00 LT. It should be noted that the spatial resolution of each parameter is lower than those derived by Wu et al. (2008), who used 9 GPS receivers around the northern EIA crest region. Since only a few GPS receivers were distributed around the magnetic equator, we are not about to discuss the EIA trough position. 
(a)

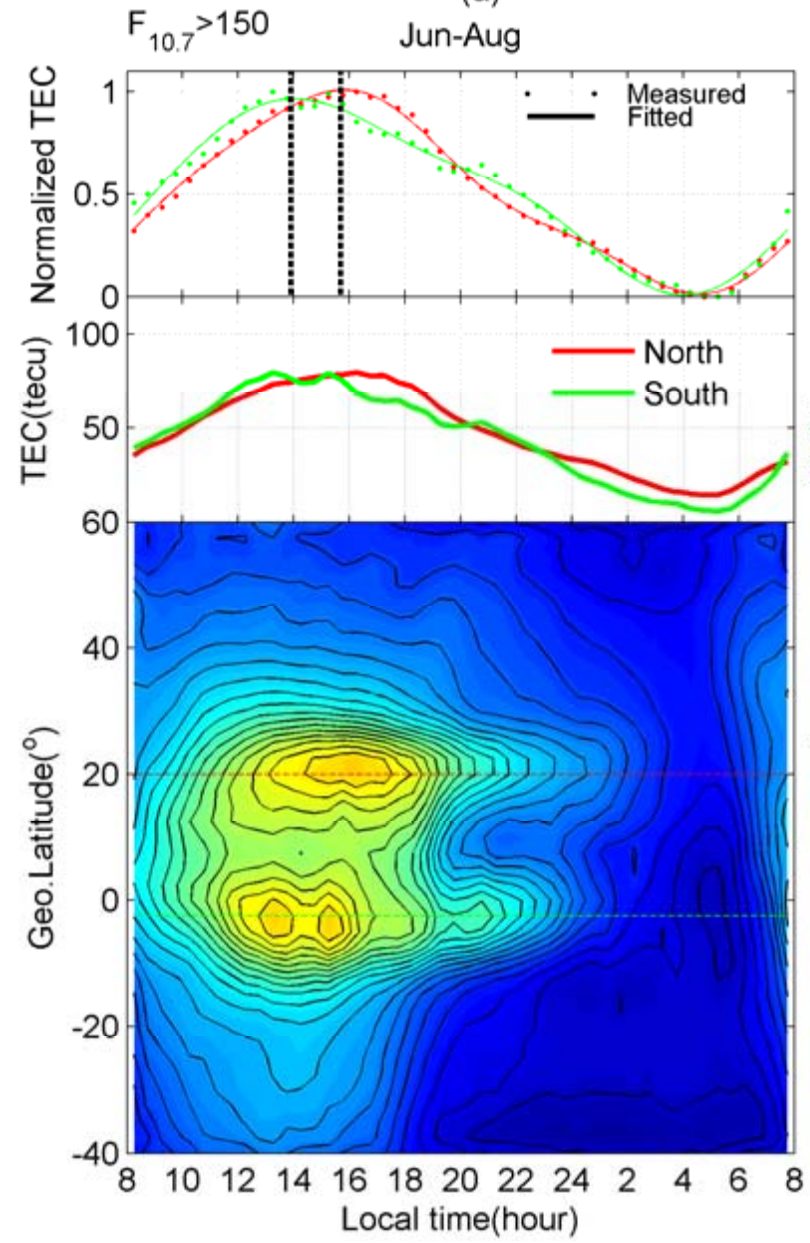

(b)

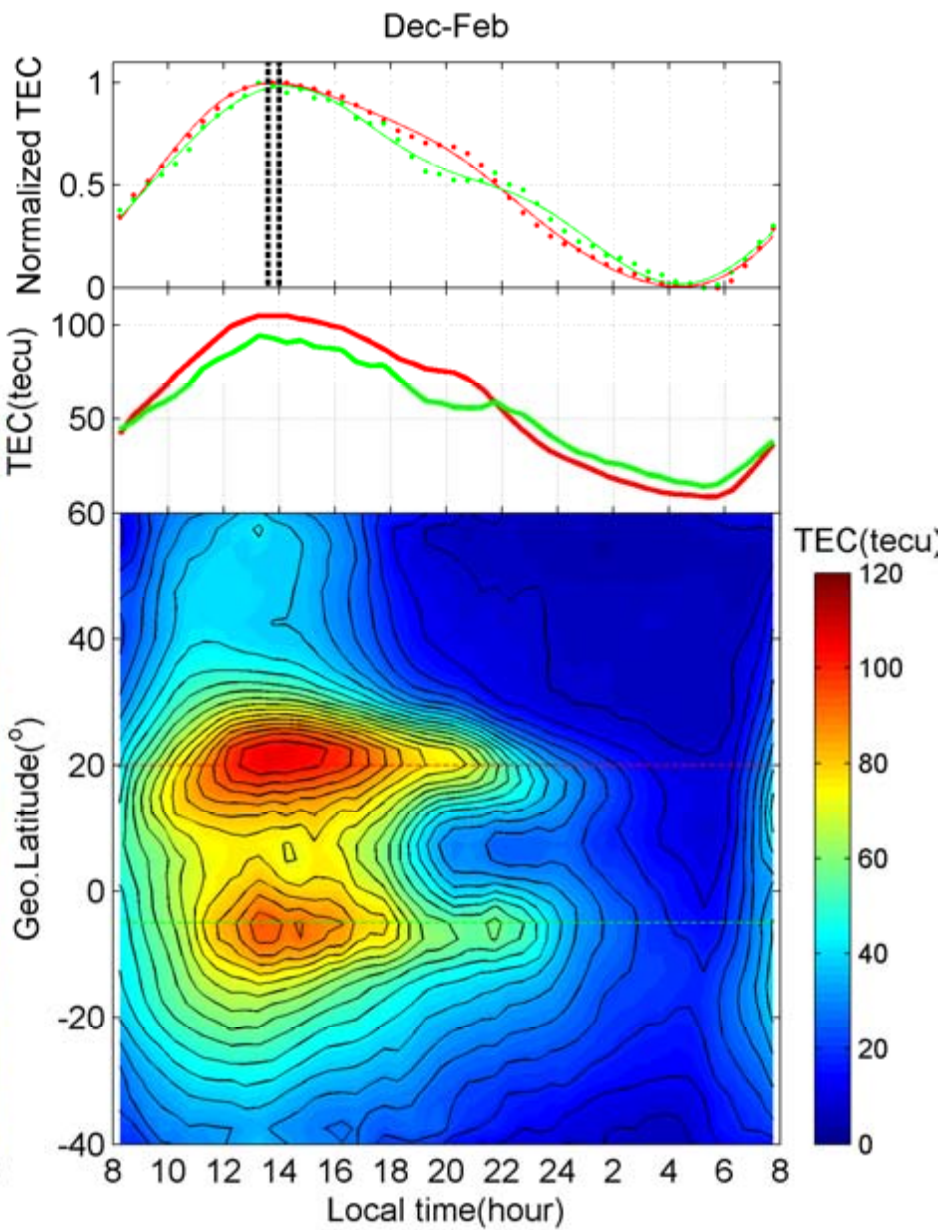

Fig. 5. Mean variation of EIA during June-August (left) and December-February (right) under the condition $\mathrm{F}_{10.7}>150$ (bottom panels). The horizontal line indicates where the most developed EIA crest is, both for northern (red) and southern (green) one. The middle panels show the diurnal variation of the crests. The top panels illustrate the time difference of the appearance of peak value for the normalized diurnal variation. The dots represent the measured value and the lines the fitted.

\section{Results and discussion}

\subsection{Seasonal dependence of the EIA crest}

Figure 3 shows, from top to bottom, the daily $\mathrm{F}_{10.7}$ index, the strength $I_{n c}\left(I_{s c}\right)$, the local time $T_{n c}\left(T_{s c}\right)$ and the latitude $L_{n c}\left(L_{s c}\right)$ of the northern (southern) crest at the time of its maximum TEC value (referred to hereafter as "EIA crest") from 1996-2004. The monthly mean values (data with daily $K_{p}>3$ are excluded) are plotted as red solid lines. It is clear that the values of daily $I_{n c}\left(I_{s c}\right)$ have a semiannual variation with two maxima occurring in autumn and spring and two minima in winter and summer. Furthermore, the amplitude of this semiannual variation is shown to be obviously modulated by the solar activity. The location of daily EIA crest reveals quite a great variability in both local time and latitude as seen from $T_{n c}\left(T_{s c}\right)$ and $L_{n c}\left(L_{s c}\right)$. It can be seen from the monthly mean that the latitude of EIA crest $L_{n c}\left(L_{s c}\right)$ tends to move equatorward during low solar activity, which was also revealed by Huang and Cheng (1996). During 1996-1997, the crests were shown to move equatorward several degree especially for the northern part. This could be caused by the ambiguous EIA structure during low solar activity. However, some seasonal trend can be observed as illustrated in Fig. 3 that crests tend to shrink equatorward at June in $L_{S c}$ during 1996-1997 and in $L_{n c}$ during 1997. The variation of northern crest with higher resolution during 1996-1997 can be referred to $\mathrm{Wu}$ et al. (2004).

In order to investigate the seasonal variation of EIA crests in more details and compare the results with the previous studies, the data was reorganized into monthly bins. To remove the effect of the geomagnetic disturbance, we only use data with a condition of daily $K_{p}<=3$. Note that for $L_{n c}$, the data during 1996-1997 were excluded to avoid a large 

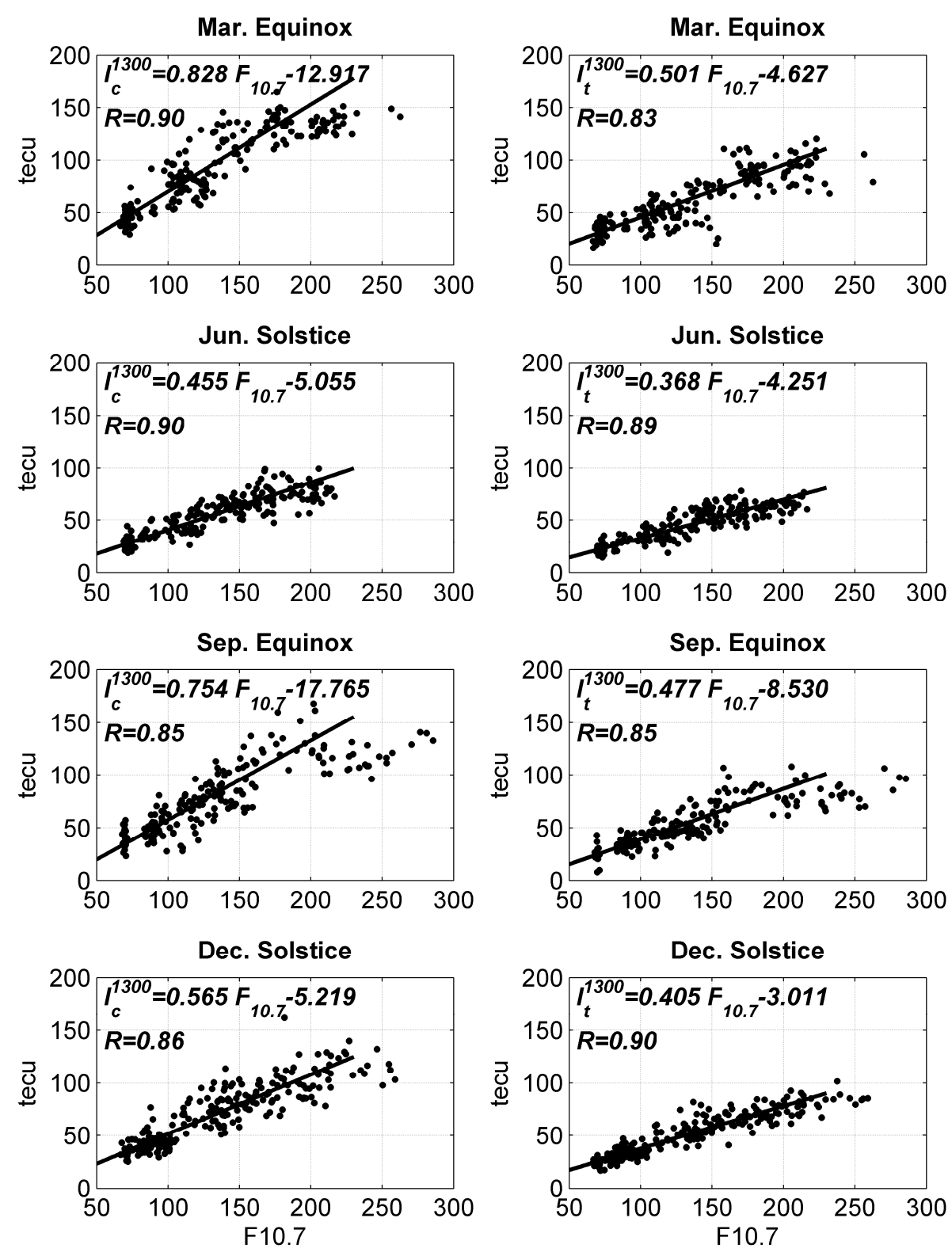

Fig. 6a. Solar activity (F10.7) dependence of noontime (13:00 LT) TEC in different seasons for two latitude regions for the (left) EIA crest, (right) EIA trough.

standard deviation. Figure 4 gives statistical results of every parameter of EIA crest. The vertical bars indicate the standard deviations of the observed quantities which can be used to measure the range of scatters of the latitudes and occurrence times of the daily EIA crests. According to Fig. 4, several conclusions can be drawn in the following: (1) The values at both the EIA crests, $I_{n c} / F_{10.7}$ and $I_{s c} / F_{10.7}$ subtracting the effect of solar activity, show evident semiannual variations with peaks around equinox. Besides, annual asymmetry, indicated by greater value in January than in July at both the crest regions, is also very clear. This means that no winter anomaly appeared in the southern crest region which is consistent with the result of global ionospheric map (GIM) TEC
(Zhao et al., 2007). (2) The latitude of EIA crest $\left(L_{n c} / L_{s c}\right)$ shows a seasonal dependence. For the northern crest, $L_{n c}$ was a slightly northward in equinoctial months than in solsticial months and this is consistent with the result of $\mathrm{Wu}$ et al. (2008). For the southern crest, $L_{s c}$ was much more equatorward from June to August than the values at equinoctial month and December. It seems that a seasonal change of the latitude position of the southern EIA crest is more evident than that of the northern one. (3) There is a tendency for the northern EIA crest (seen from $T_{n c}$ ) to appear earlier in winter and later in summer, while this is not the case for the southern crest. 

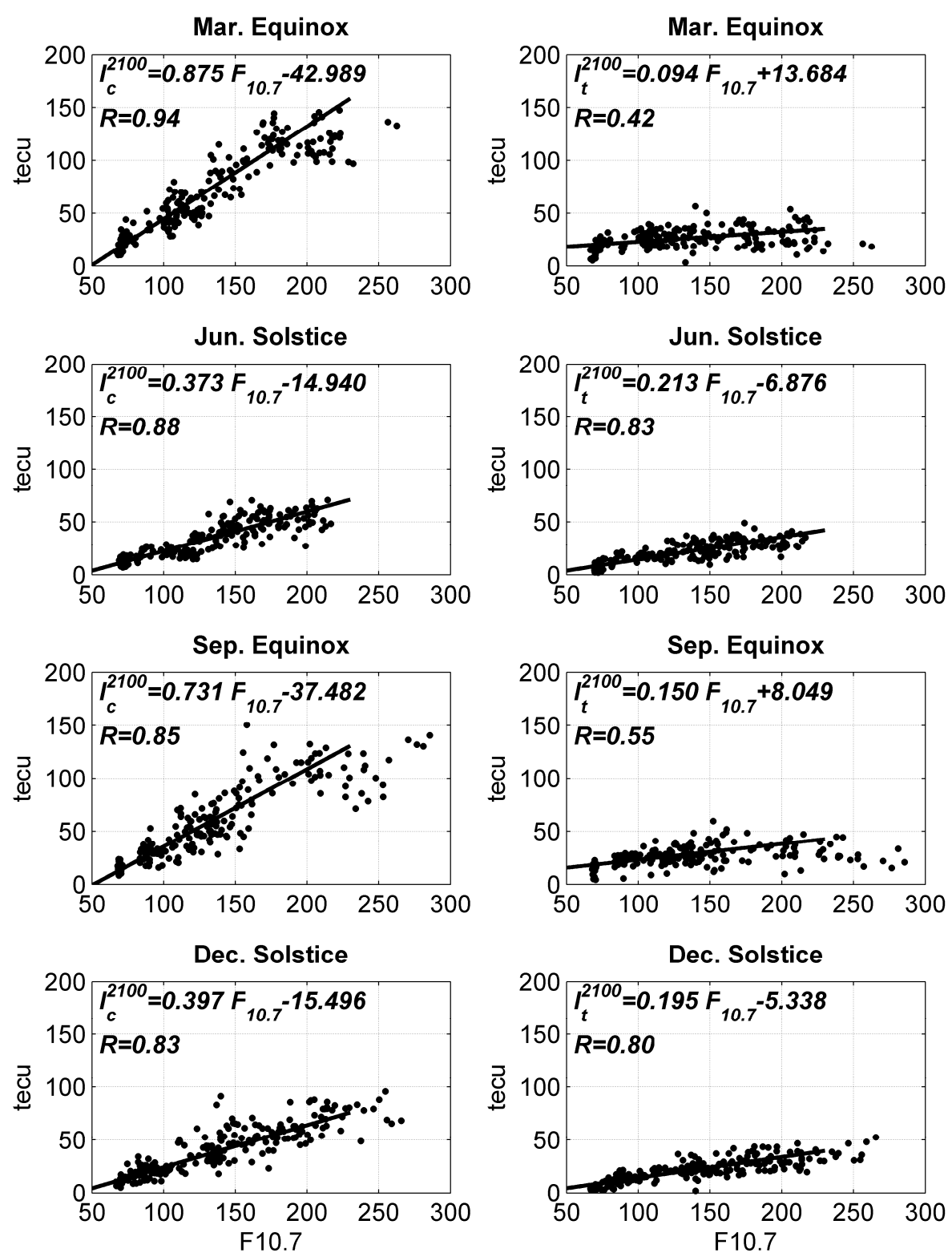

Fig. 6b. Same as Fig. 6a but for the post-sunset sector 21:00 LT.

Most features for the northern crest described above have been confirmed by the past studies (Walker et al., 1991; Huang and Cheng, 1996; Wu et al., 2008). However, northsouth asymmetry of the appearance time of the most developed EIA was not addressed. As shown in the bottom panel of Fig. $4, T_{n c}$ precedes $T_{s c} 1.1 \sim 1.3 \mathrm{~h}$ during JuneAugust while $T_{s c}$ precedes $T_{n c}$ no more than half an hour at November-January. To give a straightforward description, we plot the average EIA structure during June-August and December-February, respectively, for all the data during high solar activity $\left(\mathrm{F}_{10.7}>150\right)$ as shown in the bottom panel of Fig. 5. Slices across the crest regions were singled out and plotted in the middle panels with the red lines denoting the northern crest and the green as the southern. The top panels of Fig. 5 show the diurnal TEC variations of the crests to be normalized within $[0,1]$. The dots denote the observed values while the lines represent the fitted values through the Fourier decomposition in order to obtain the diurnal maxima position. As indicated by the vertical dashed lines in Fig. 5a, the maxima of the northern EIA crest appears nearly $2 \mathrm{~h}$ after that of the southern one during June-August. This can be explained through the effects of daytime summer-winter transequatorial meridional winds (Rishbeth, 1972). During summer, the daytime thermal pressure bulge of the thermosphere locates at the midlatitude in the summer hemisphere, and neutral winds blow away 
from the thermospheric pressure bulge. In the equatorial region, transequatorial neutral winds blowing from the summer hemisphere toward the winter hemisphere in the magnetic meridian can readily move the ionization along the magnetic field lines. These summer-winter transequatorial winds either increase or decrease the rate of diffusion of ionization from the magnetic equatorial region toward the winter or summer hemisphere crest via the normal EIA mechanism. Consequently, the development of summer EIA crest should be retarded, and winter EIA crest should be enhanced. Meanwhile, the transequatorial winds also changes the recombination rate by lifting/lowering the ionospheric height on either side of the equator and, hence, increase/decrease the electron density. This process was most evident at middle latitudes and less significant at the EIA crest region due to small magnetic dip angle and retarding diffusion effect. F-layer peak height was observed to be anti-correlated with the peak electron density at EIA crest (Fesen et al., 1989). It is known that the local production rate of ionization is greater in the winter hemisphere due to dynamical transport increasing the $\mathrm{O} / \mathrm{N}_{2}$ ratio (Rishbeth, 1998). However, this effect is more adaptable to explain the winter anomaly at middle latitudes. The hemispheric difference in the $\mathrm{O} / \mathrm{N}_{2}$ ratio is small in the low latitudes during the daytime.

Figure $5 \mathrm{~b}$ shows that the maximum of the southern EIA crest appears only half an hour after that of the northern one during December-February. Little difference is seen between the time when maximum appears at two crests. We have checked the $f \circ \mathrm{F} 2$ variation using ionosonde data at Okinawa $\left(26.7^{\circ} \mathrm{N}, 128.2^{\circ} \mathrm{E}\right)$ and Darwin $\left(12.5^{\circ} \mathrm{S}, 130.9^{\circ} \mathrm{E}\right)$ and a similar result was obtained. However, this character was not observed by Tsai et al. (2001) which studied the southern anomaly at the Indian sector. Transequatorial winds still effects the works producing the evident north-south asymmetry because the TEC at northern (winter) crest increases faster than that at the southern (summer) one during 08:0012:00 LT. However, the subsolar point is much closer to the geomagnetic equator in the summer Northern Hemisphere than in the summer Southern Hemisphere and results in different types of transequatorial winds at EIA region. Furthermore, the local time of the appearance of daily maximum at EIA crest not only depends on the transequatorial winds, but also the strength of the equatorial electric fields and neutral composition. According to the quiet time equatorial upward drift model (Scherliess and Fejer, 1999), the equatorial zonal electric field develops quickly in the morningnoon sector and diminishes quickly after local noon for JuneAugust. However, this electric field remains at a considerable strength, $8-10 \mathrm{~m} / \mathrm{s}$ greater than during June-August, in the afternoon sector for December-January around $120^{\circ} \mathrm{E}$. This may lead to the balance of the effect of electric field and equatorward thermospheric wind which tends to diminish in the afternoon sector according to HWM 93 model (Hedin et al., 1996). Furthermore, the TEC value in DecemberFebruary is greater than that in June-August, and this may
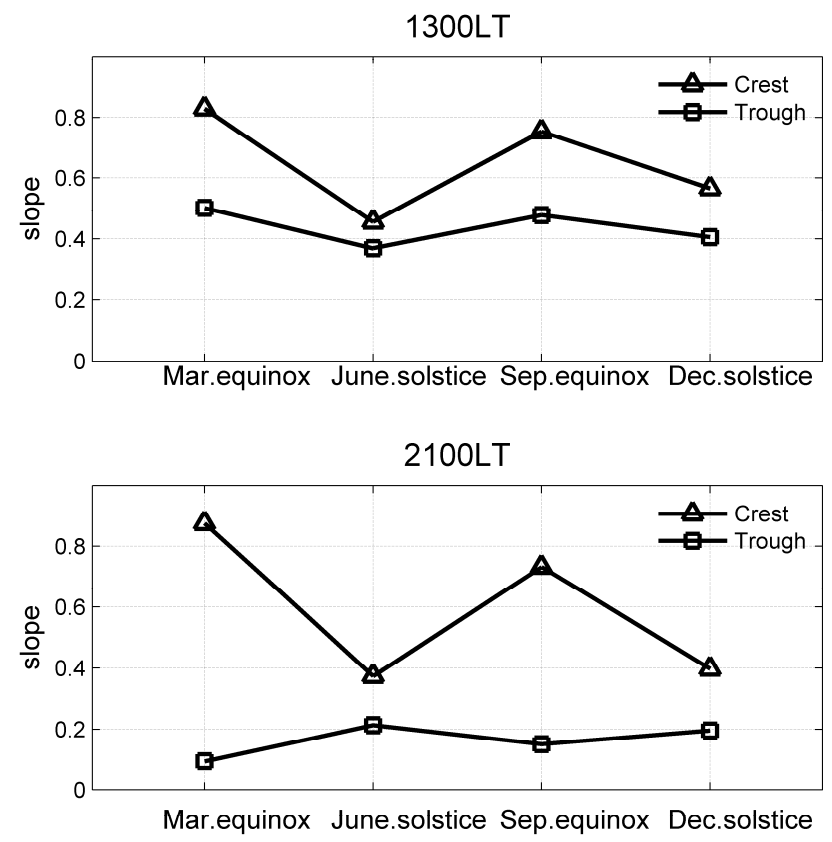

Fig. 7. Slopes of the solar activity dependence of TEC in different seasons in the EIA crest and trough regions for noon and post-sunset sectors. Slopes are obtained by least squares fitting of data points for $F_{10.7}<200$ shown in Fig. 6.

result in an increase of the retarding effect of ion-drag on the daytime meridional winds (Walker et al., 1991). The mechanism of the asymmetry in the local time appearance of maximum EIA crest as well as its longitude dependence needs to resort to the model simulation for detailed investigation which is beyond the scope of this paper.

\subsection{Solar activity dependence of the EIA structure for noon and post-sunset sectors}

In this section, we are about to investigate the solar activity dependence of the EIA structure characterized by $I_{c}^{1300}$, $I_{t}^{1300}$ and $\mathrm{CTR}^{1300}$ in the noon and $I_{c}^{2100}, I_{t}^{2100}$ and CTR ${ }^{2100}$ in the post-sunset sector. As shown in Fig. 6a, b, in order to show the relationship for the strength of EIA crest and trough at noon as well as in the post-sunset sector with respect to the $\mathrm{F}_{10.7}$, a robust linear regression method was used to derive at the solar activity dependence of the EIA based on 31-day data centered at equinox and solstice under the geomagnetic condition $K_{p}<=3$. The significance of the solar activity dependence can be represented by the slopes of the fitted curves, and it has been summarized in Fig. 7. In the noon sector, a significantly positive correlation prevails for solar activity levels with $\mathrm{F}_{10.7}<200$ at both the crest and trough regions as seen in Fig. 6a. Considering saturation effect around equinox when $F_{10.7}$ exceeds 200, the slopes have been calculated without data samples at $F_{10.7}>200$ for all cases in Fig. 6. It is apparent in Fig. 7 that the solar activity 

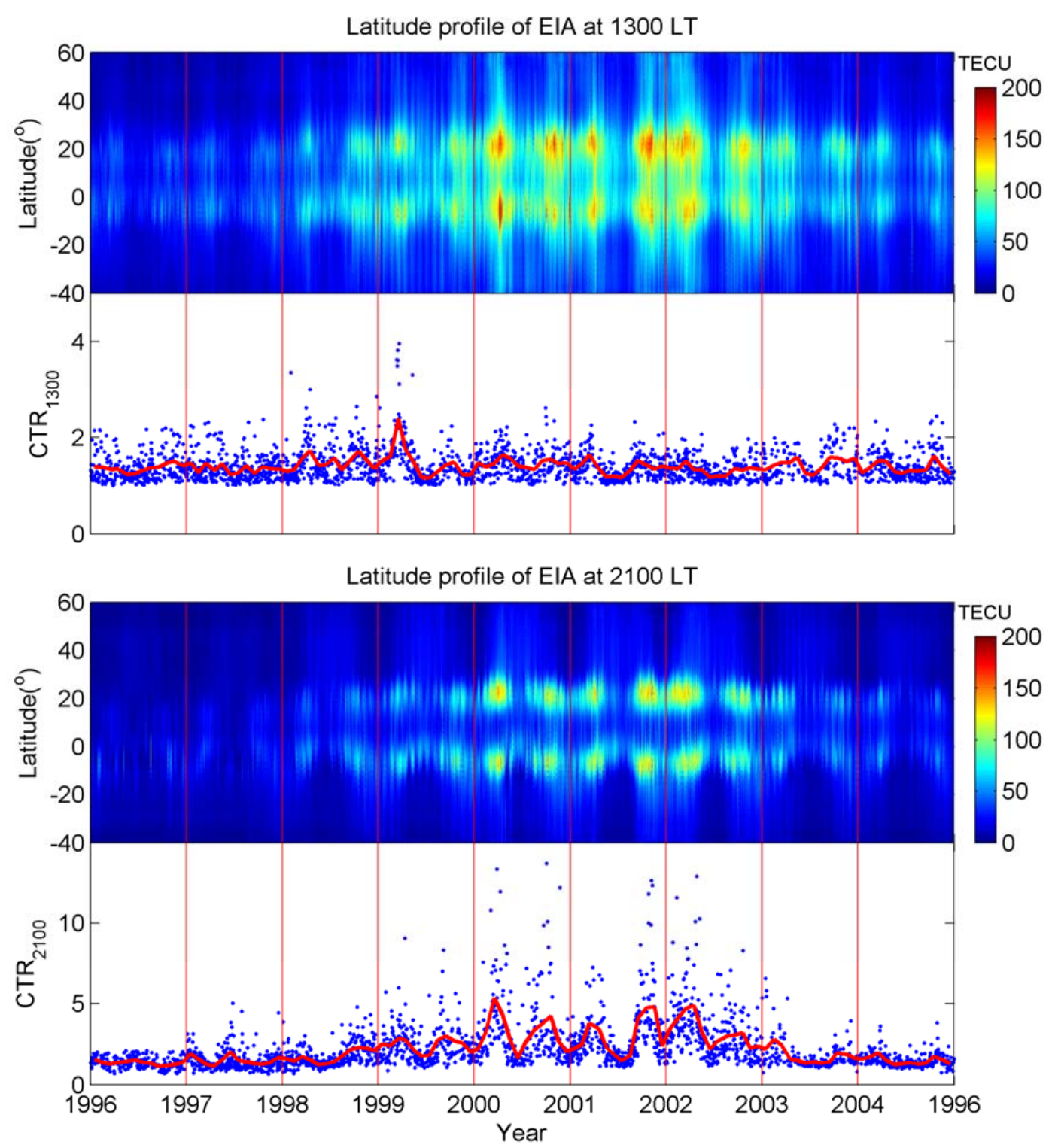

Fig. 8. Latitude profile of EIA and crest-to-trough ratio around 13:00 and 21:00 LT during 1996-2004. The red lines denote the monthly mean value.

dependence is stronger in the EIA crest region than in the trough region. This is because the fountain effect tends to remove plasma from the dip equator and to deposit it in the crest regions. When superimposed on the enhanced photoionization with increasing solar activity levels, it results in a stronger density enhancement with $\mathrm{F}_{10.7}$ in the crest region than it does in the trough region during the daytime (Liu et al., 2007). Furthermore, for the crest region, slopes are higher around the equinox and lower near the solstice, and more specifically highest at March equinox and lowest at June solstice. In contrast, the seasonal difference in the EIA trough region was not that significant as in the crest region. For the post-sunset sector, the seasonal variation of the solar activity dependence at EIA crest resembles that in the noon sector. However, in the EIA trough region, the slopes were much lower. Figure $6 \mathrm{~b}$ shows that $I_{t}^{2100}$ tends to decrease with $F_{10.7}$ when $F_{10.7}>200$ around equinox and the correlation coefficient $R$ is around $0.4 \sim 0.5$. A similar result was also obtained by Liu et al. (2007). Their result indicates that after sunset, when $P\left(P=\mathrm{F}_{10.7}+\mathrm{F}_{10.7 A}\right)$ exceeds 180 , the $N_{e}$ at $\sim 400 \mathrm{~km}$ shows significant increases at the crest region and became unrelated in the trough region with respect to the solar activity, whereas this situation is clearly dependant on the season.

Another important parameter of the EIA is CTR which is directly related to the fountain effects. In the East-Asian 

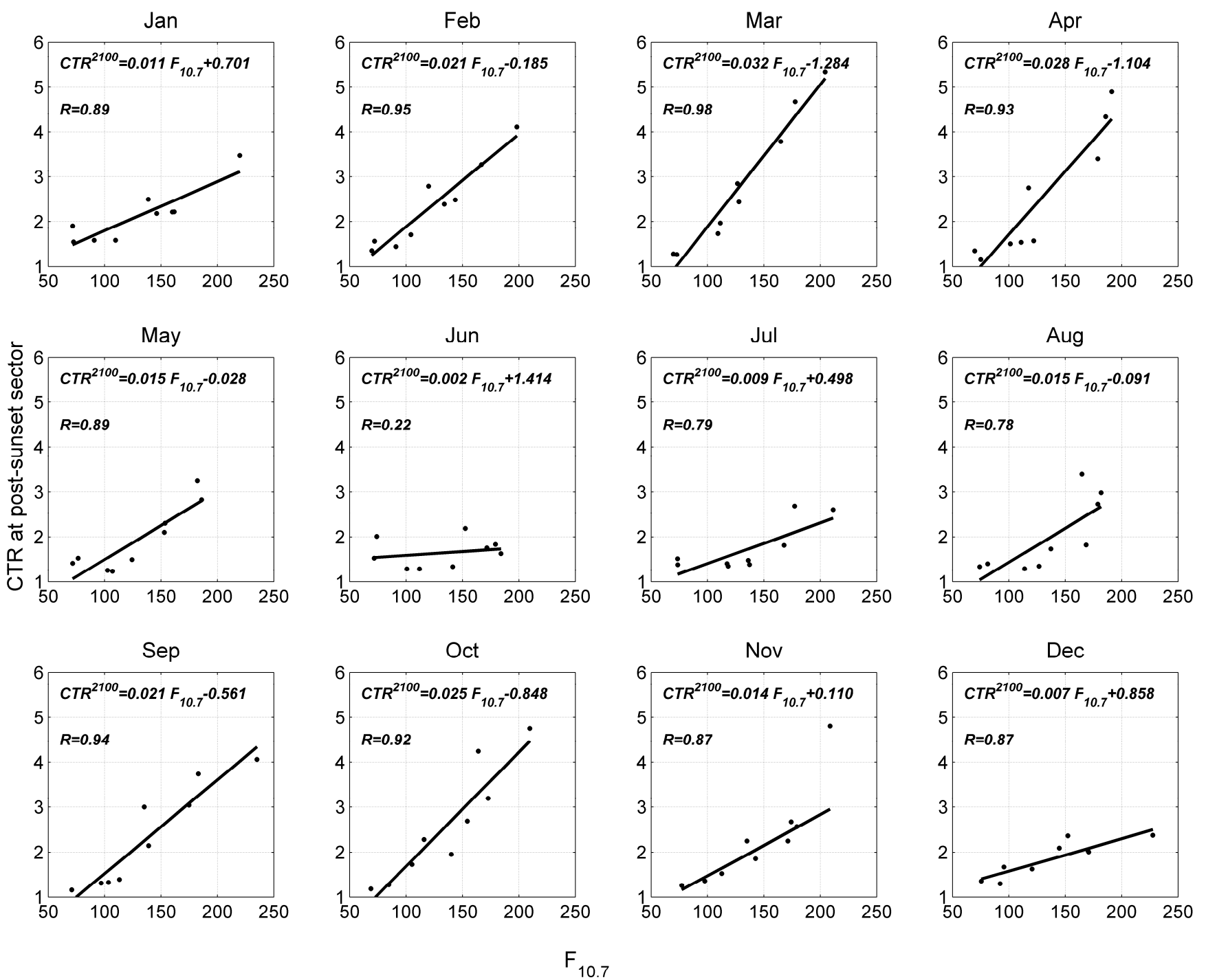

Fig. 9. The linearity of monthly post-sunset CTR with monthly solar flux for all months. The straight line is the robust fit value.

region where no direct measurement of equatorial zonal electric field is present, the CTR can provide indirect information of the electric field, though is not accurate (Basu et al., 2004). Mendillo et al. (2000) found the utility of this index to be an indicator of the occurrence of equatorial spread $\mathrm{F}$ (ESF).

Figure 8 illustrates the evolution of $\mathrm{CTR}^{1300}$ in the noon and $\mathrm{CTR}^{2100}$ in the post-sunset sector associated with latitude profile of EIA during 1996-2004. The red lines denote the monthly mean value. Semiannual trend was identified in $\mathrm{CTR}^{1300}$ though it shows a year-to-year variability. No solar activity dependence was observed in $\mathrm{CTR}^{1300}$ since the daytime F-region equatorial electric field was controlled by the E-region dynamo modulated by the tides in the lower atmosphere (Fejer et al., 1991b; Stening, 1992). The analysis of the wind data of UARS satellite by Burrage et al. (1995) showed that there are very obvious semiannual variations of the amplitude of the diurnal tide $(1,1)$ mode at the height of $95 \mathrm{~km}$ in the period of October 1991-March 1995. Forbes (1981) pointed out that the diurnal tide $(1,1)$ mode in the ionospheric E-layer is the direct driving source for the equatorial electrojet. Therefore, there must be the semiannual variation in the intensity of the equatorial electrojet, which was clearly identified at a global scale by Alken and Maus (2007). Figure 8 also shows that around the March equinox of 1999, the amplitude of the CTR ${ }^{1300}$ was larger compared to the other year. This corresponds to the northward moving of the northern EIA crest observed by Wu et al. (2008) indicating an expansion of EIA. We are not very certain of what happened in the lower atmosphere which resulted in a very effective fountain effect during this period.

As illustrated in the bottom panel of Fig. 8 for the postsunset sector, CTR ${ }^{2100}$ shows a very strong dependence of 
solar activity compared with the noon sector. This is apprehensible because the pre-reversal enhancement of eastward electric field in the dusk sector increases significantly with solar activity as reviewed by Fejer (1991a). At nighttime in the trough region the loss of the plasma density due to the enhanced fountain effect cannot be offset by the photoionization like the noon sector. Figure 9 plots the monthly mean $\mathrm{CTR}^{2100}$ versus the corresponding $\mathrm{F}_{10.7}$ at each month and applied the robust regression method. It was shown that CTR grows linearly with solar flux. The slope is larger in the equinox season than that in the December solstice and smallest during June solstice, which is similar to the results of the Whalen (2004) for the NmF2 at its maximum near 21:00 LT. The cause for this has been demonstrated by Whalen (2004) and Basu et al. (2004) to be the $\boldsymbol{E} \times \boldsymbol{B}$ vertical drift. The equatorial $\boldsymbol{E} \times \boldsymbol{B}$ vertical drift exhibits a linear relation to the solar activity in all seasons except during June solstice due to the saturation effect (Fejer, 1991b).

\section{Summary}

We have shown in this paper the main characteristics of the EIA structure in the Asian-Australian region during 19962004. Findings can be summarized in the following:

1. The magnitude of the most developed EIA crest is larger at equinox than at solstice. More specifically it is largest at March equinox and smallest at June solstice.

2. The latitude and local time position of the EIA crest have a seasonal variation but show a north-south asymmetry. The northern crest of EIA was expanded during equinox indicating a weak semiannual variation while the southern crest was inhibited during June-August presenting a strong seasonal variation. Meanwhile, the local time of the northern crest appeared $1.3 \mathrm{~h}$ earlier than that of the southern crest in June while this is not the case vice versa at December.

3. Solar activity increase rate is more significant at crest region for both the noon and post-sunset sector and less evident in the EIA trough region especially during the equinox in the post-sunset sector.

4. The crest-to-trough ratio, CTR, was shown to vary differently during noon and post-sunset sector. The CTR for the latter has a clear linear dependence with solar flux which differed from that at noon due to the dynamo effect in the lower atmosphere. However, both the ratios exhibit a semiannual variation with two peaks at equinox and a valley at June solstice.

In the future, we are ready to investigate the relationship between the CTR and the equatorial drift either measured by ROCSAT-1 satellite or derived by $\Delta H$ (difference of magnetic $\mathrm{H}$ component near the magnetic equator) in the Asian-
Australian sector. If the two parameters can be parameterized, the CTR can be used to predict the equatorial drift when the measurement is absent in this region.

Acknowledgements. The authors acknowledge IGS for providing the GPS data in the web site. The $\mathrm{F}_{10.7}$ index was downloaded from the SPIDR web http://spidr.ngdc.noaa.gov/. This research was funded by National Natural Science Foundation of China (40804041) and National Important Basic Research Project (2006CB806306). This work was also supported by National Natural Science Foundation of China (40636032, 40725014).

Topical Editor M. Pinnock thanks two anonymous referees for their help in evaluating this paper.

\section{References}

Abdu, M. A.: Equatorial ionosphere-thermosphere system: Electrodynamics and irregularities, Adv. Space Res., 35, 771-787, 2005.

Alken, P. and Maus, S.: Spatio-temporal characterization of the equatorial electrojet from CHAMP, Ørsted, and SAC-C satellite magnetic measurements, J. Geophys. Res., 112, A09305, doi:10.1029/2007JA012524, 2007.

Basu, B., Retterer, J. M., de La Beaujardière, O., Valladares, C. E., and Kudeki, E.: Theoretical relationship between maximum value of the postsunset drift velocity and peak-to-valley ratio of anomaly TEC, Geophys. Res. Lett., 31, L03807, doi:10.1029/2003GL018725, 2004.

Breed, A. M.: Investigation of the ionosphere over Australia using satellite transmissions, PhD thesis, School of Applied Physics, University of South Australia, 1996.

Burrage, M., Hagan, M., Skinner, W., Wu, D., and Hays, P.: LongTerm Variability in the Solar Diurnal Tide Observed by HRDI and Simulated by the GSWM, Geophys. Res. Lett., 22, 26412644, 1995.

Dabas, R. S., Singh, L., Garg, S., Das, R. M., Sharma, K., and Vohra, V. K.: Growth and decay of a post-sunset equatorial anomaly at low latitudes: Control of $\boldsymbol{E} \times \boldsymbol{B}$, neutral winds and daytime electrojet strength, J. Atmos. Sol. Terr. Phys., 68, 16221632, 2006.

Fejer, B. G.: Low latitude electrodynamic plasma drifts: a review, J. Atmos. Terr. Phys., 53, 677-693, 1991.

Fejer, B. G., de Paula, E., González, S., and Woodman, R.: Average Vertical and Zonal F Region Plasma Drifts Over Jicamarca, J. Geophys. Res., 96, 13901-13906, 1991.

Fesen, C. G., Growley, G., and Roble, R. G.: Ionospheric effects at low latitudes during the March 22, 1979, geomagnetic storm, J. Geophys. Res., 94, 5405-5417, doi:10.1029/JA094iA05p05405, 1989.

Forbes, J. M.: The equatorial electrojet, Rev. Geophys. Space Phys. 19, 469-504, 1981.

Golton, E. and Walker, G. O.: Observations of ionospheric electron content across the equatorial anomaly at sunspot minimum, J. Atmos. Terr. Phys., 33, 1-11, 1971.

Heelis, R. A.: Electrodynamics in the low and middle latitude ionosphere: a tutorial, J. Atmos. Sol. Terr. Phys., 66, 825-838, 2004.

Huang, Y.-N. and Cheng, K.: Solar cycle variations of equatorial ionospheric anomaly in total electron content in the Asian region, J. Geophys. Res., 101, 24513-24520, 1996. 
Jakowski, N., Sardon, E., Engler, E., Jungstand, A., and Klhn, D.: Relationships between GPS-signal propagation errors and EISCAT observations, Ann. Geophys., 14, 1429-1436, 1996, http://www.ann-geophys.net/14/1429/1996/.

Klobuchar, J. A.: Ionospheric effects on GPS, in: Global Positioning System: Theory and application Vol. 1, edited by: Parkinson, B. W. and Spilker, J. J., American Institute of Aeronautics and Astronautics INC., 1996.

Klobuchar, J. A.: Ionospheric effects on GPS, GPS World, 48-51, 1991.

Lanyi, G. E. and Rolh, T.: A comparison of mapped and measured total ionospheric electron content using global positioning system and beacon satellite observations, Radio Sci., 23, 483-492, 1988.

Liu, H., Stolle, C., Förster, M., and Watanabe, S.: Solar activity dependence of the electron density in the equatorial anomaly regions observed by CHAMP, J. Geophys. Res., 112, A11311, doi:10.1029/2007JA012616, 2007.

Mendillo, M., Bosheng, L., and Aarons, J.: The application of GPS observations to equatorial aeronomy, Radio Sci., 35, 885-904, 2000.

Rishbeth, H.: Thermospheric winds and the F-region: A review, J. Atmos. Terr. Phys., 34, 1-41, 1972.

Rishbeth, H.: How the thermospheric circulation affects the ionospheric F2-layer, J. Atmos. Sol. Terr. Phys., 60, 1385-1402, 1998.

Rishbeth, H., Müller-Wodarg, I. C. F., Zou, L., Fuller-Rowell, T. J., Millward, G. H., Moffett, R. J., Idenden, D. W., and Aylward, A. D.: Annual and semiannual variations in the ionospheric F2-layer: II. Physical discussion, Ann. Geophys., 18, 945-956, 2000 , http://www.ann-geophys.net/18/945/2000/.

Sardón, E., Rius, A., and Zarraoa, N.: Estimation of the receiver differential biases and the ionospheric total electron content from Global Positioning System observations, Radio Sci., 29, 577586, 1994.

Scherliess, L. and Fejer, B. G.: Radar and satellite global equatorial F region vertical drift model, J. Geophys. Res., 104, 6829-6842, 1999.

Stening, R. J.: Modeling the low-latitude F-region, A review, J. Atmos. Terr. Phys., 54, 1387-1412, 1992.

Titheridge, J. E.: The total electron content of the southern midlatitude ionosphere, 1965-1971, J. Atmos. Terr. Phys., 35, 9811001, 1972.

Tsai, H. F., Liu, J. Y., Tsai, W. H., Liu, C. H., Tseng, C. L., and Wu, C. C.: Seasonal variations of the ionospheric total electron content in Asian equatorial anomaly regions, J. Geophys. Res., 106(A12), 30363-30369, 2001.
Walker, G. O. and Ma, J. H. K.: Influence of solar flux and the equatorial electrojet on the diurnal development of the latitude distribution of total electron content in the 'equatorial anomaly', J. Atmos. Terr. Phys., 34, 1419-1424, 1972.

Walker, G. O. and Poon, C. B.: The early morning development and the evening decay of electron content-latitude profiles at low latitudes and their dependence upon solar declination, J. Atmos. Terr. Phys., 39, 1145-1154, 1977.

Walker, G. O., Wong, W. Y., Huang, Y. N., Kikuchi, T., Soegijo, J., Badillo, V., and Szuszczewicz, E. P.: Periodic behaviour of the ionosphere in South East Asia on storm and quiet days during the May/June SUNDIAL campaign, 1987, J. Atmos. Terr. Phys., 53, 627-641, 1991.

Walker, G. O., Ma, J. H. K., and Golton, E.: The equatorial ionospheric anomaly in electron content from solar minimum to solar maximum for South East Asia, Ann. Geophys., 12, 195-209, 1994, http://www.ann-geophys.net/12/195/1994/.

Whalen, J. A.: Linear dependence of the postsunset equatorial anomaly electron density on solar flux and its relation to the maximum prereversal $\boldsymbol{E} \times \boldsymbol{B}$ drift velocity through its dependence on solar flux, J. Geophys. Res., 109, A07309, doi:10.1029/2004JA010528, 2004.

Whalen, J. A.: Dependence of the equatorial anomaly and of equatorial spread $\mathrm{F}$ on the maximum prereversal $\boldsymbol{E} \times \boldsymbol{B}$ drift velocity measured at solar maximum, J. Geophys. Res., 108(A5), 1193, doi:10.1029/2002JA009755, 2003.

Wu, C. C., Fry, C. D., Liu, J. Y., Liou, K., and Tseng, C. L.: Annual TEC variation in the equatorial anomaly region during the solar minimum: September 1996-August 1997, J. Atmos. and SolarTerr. Phys., 66, 199-207, 2004.

Wu, C. C., Liou, K., Shan, S. J., and Tseng, C. L.: Variation of ionospheric total electron content in Taiwan region of the equatorial anomaly from 1994 to 2003, Adv. Space Res., 41, 611-616, 2008.

Zhao, B., Wan, W., and Liu, L.: Responses of equatorial anomaly to the October-November 2003 superstorms, Ann. Geophys., 23, 693-706, 2005, http://www.ann-geophys.net/23/693/2005/.

Zhao, B., Wan, W., Liu, L., Mao, T., Ren, Z., Wang, M., and Christensen, A. B.: Features of annual and semiannual variations derived from the global ionospheric maps of total electron content, Ann. Geophys., 25, 2513-2527, 2007, http://www.ann-geophys.net/25/2513/2007/. 